University of Nebraska - Lincoln

DigitalCommons@University of Nebraska - Lincoln

Faculty Publications from the Harold W. Manter Laboratory of Parasitology

2-1977

\title{
Life History and Host Specificity of Mediorhynchus centurorum Nickol 1969 (Acanthocephala: Gigantorhynchidae)
}

\author{
Brent B. Nickol \\ University of Nebraska - Lincoln, bnickol1@unl.edu
}

Follow this and additional works at: https://digitalcommons.unl.edu/parasitologyfacpubs

Part of the Parasitology Commons

Nickol, Brent B., "Life History and Host Specificity of Mediorhynchus centurorum Nickol 1969

(Acanthocephala: Gigantorhynchidae)" (1977). Faculty Publications from the Harold W. Manter Laboratory of Parasitology. 356.

https://digitalcommons.unl.edu/parasitologyfacpubs/356

This Article is brought to you for free and open access by the Parasitology, Harold W. Manter Laboratory of at DigitalCommons@University of Nebraska - Lincoln. It has been accepted for inclusion in Faculty Publications from the Harold W. Manter Laboratory of Parasitology by an authorized administrator of DigitalCommons@University of Nebraska - Lincoln. 


\title{
LIFE HISTORY AND HOST SPECIFICITY OF MEDIORHYNCHUS CENTURORUM NICKOL 1969 (ACANTHOCEPHALA: GIGANTORHYNCHIDAE)
}

\author{
Brent B. Nickol \\ School of Life Sciences, University of Nebraska-Lincoln, \\ Lincoln, Nebraska 68588
}

ABSTRACT: Examination of 1905 arthropods from a swamp and surrounding pasture in southern Louisiana revealed larval specimens of Mediorhynchus centurorum in 8 of 228 woodroaches, Parcoblatta pensylvanica, but in no other species. The life cycle was confirmed by feeding eggs of $M$. centurorum to laboratory-reared woodroaches. Cystacanths later recovered from the woodroaches developed into mature worms when pipetted into esophaguses of red-bellied woodpeckers, Centurus carolinus; redheaded woodpeckers, Melanerpes erythrocephalus; yellow-shafted flickers, Colaptes auratus; and a hairy woodpecker, Dendrocopos villosus. Infection was achieved in all woodpeckers fed cystacanths at least 47 days old and the mean prepatent period was 35 days. Cystacanths fed starlings, Sturnus vulgaris, and red-winged blackbirds, Agelaius phoeniceus, did not produce infections although cystacanths from the same pool were infective to control woodpeckers.

Larval development of Mediorhynchus centurorum in woodroaches did not differ significantly from that of $M$. grandis in grasshoppers. M. centurorum is the only species of the Gigantorhynchidae for which the life cycle has been confirmed by laboratory infections using an intermediate host species known infected in nature.

A high degree of vertebrate host specificity was reported by Nickol (1969) in the original description of Mediorhynchus centurorum. He noted that 900 birds of 68 species in 30 families from Louisiana were examined and that, even though many of them came from the same or similar habitats, $M$. centurorum was found in only red-bellied woodpeckers, Centurus carolinus. Further, 76 of the birds representing 20 species, including 25 of four other species of Picidae, were collected from a single, small wooded area from which 10 of 16 red-bellied woodpeckers harbored M. centurorum. Most acanthocephalan species, including other members of Mediorhynchus, are not nearly so host specific and infect a variety of species having similar diets. Nickol (1969) reported also that $M$. centurorum penetrates deeply into the intestinal wall of its vertebrate host causing a nodule, about $5 \mathrm{~mm}$ long, to bulge into the coelom. Other species of Mediorhynchus have not been reported to cause similar nodules.

The fact that in North America no other acanthocephalan species regularly parasitizes woodpeckers and that unlike other members of the genus Mediorhynchus centurorum penetrates deeply into intestinal walls suggested that $M$. centurorum might be a usual parasite of another vertebrate species and that deep

Received for publication 27 April 1976. penetration and morphological distinctions might result from parasitizing a member of the Picidae.

To provide specimens for study of host specificity in the laboratory, an attempt was made to discover the life cycle of Mediorhynchus centurorum. Since morphologically $M$. centurorum differs consistently but only slightly from M. papillosus Van Cleave 1916, it was of particular interest whether $M$. centurorum could parasitize red-winged blackbirds, Agelaius phoeniceus, the usual host for M. papillosus, and if so whether morphological variation from woodpecker specimens would be so great that the two acanthocephalan species could not be distinguished. Susceptibility of starlings, Sturnus vulgaris, was also of interest because all of the frequently reported species of Mediorhynchus in North America (M. grandis Van Cleave 1916, M. papillosus, and M. robustus Van Cleave 1916) are known to occur in starlings.

Except for salient features related to recognition of the species and its use in the laboratory, no attempt is made to detail Mediorhynchus centurorum larval development.

\section{MATERIALS AND METHODS}

Arthropods were collected from woodpecker foraging and nesting sites and examined for Mediorhynchus centurorum larvae until natural infec- 
tions were discovered in woodroaches, Parcoblatta pensylvanica. Ootheca from a laboratory colony of wild-caught $P$. pensylvanica were used to initiate a colony of laboratory-reared woodroaches. All woodroaches used were from the laboratory-reared colony.

Woodroaches were infected with Mediorhynchus centurorum by 2 methods. In the first, eggs collected from body cavities of gravid worms were fed to woodroaches fresh or after storage in tap water at $4 \mathrm{C}$. After being held 2 days without food and water, woodroaches were placed in compartments of plastic boxes the bottoms of which had been fitted with potato slices covered with a tap water suspension of eggs. Woodroaches were allowed to feed $48 \mathrm{hr}$ on the preparation before being removed to holding boxes containing moist cotton and Purina Lab Chow. On one occasion woodroaches were allowed to feed only $5 \mathrm{~min}$ and were examined $1 \frac{1}{2} \mathrm{hr}$ later. In the second infection method, 6 groups of woodroaches were fed eggs passed naturally in woodpecker feces periodically moistened during a $48 \mathrm{hr}$ exposure period. Four of the groups were fed feces from a red-bellied woodpecker, one feces from a red-headed woodpecker, Melanerpes erythrocephalus, and one feces from a yellow-shafted flicker, Colaptes auratus. Infections in each birds had been produced from laboratory-reared cystacanths. Except for those examined $1 \frac{1}{2} \mathrm{hr}$ after feeding, woodroaches were dissected daily and the acanthocephalans were collected and prepared for microscopic study.

Fifteen cystacanths resulting from feeding Mediorhynchus centurorum eggs to laboratory-reared woodroaches were pipetted into the esophagus of a red-bellied woodpecker. The woodpecker was 1 of 2 removed from a nest before fledging and raised in captivity. Daily fecal examinations beginning 3 wk before feeding of cystacanths and continuing until acanthocephalan eggs appeared insured that no acanthocephalan was initially present and permitted determination of the prepatent period.

For study of definitive host specificity in the laboratory, cystacanths produced by laboratory infections of woodroaches were pipetted into esophaguses of woodpeckers, blackbirds, and starlings. Before use, each bird had been in captivity for at least 1 month after being caught in a mist net or removed from a nest. Daily fecal examinations beginning $2 \mathrm{wk}$ before use insured absence of acanthocephalans. Initially cystacanths were fed to one each of the following species of Picidae: Colaptes auratus; hairy woodpecker, Dendrocopos villosus; and Melanerpes erythrocephalus. In attempts to produce infections in the 3 woodpecker species, cystacanths from a group of laboratory-infected woodroaches were pooled in saline-filled Syracuse dishes. From the pool, 15 cystacanths were randomly selected and fed to one Centurus carolinus, the acanthocephalan's host species in nature and one previously demonstrated susceptible in the laboratory. Remaining cystacanths were fed, 15 each, to the other woodpeckers. Feeding of $\boldsymbol{C}$. carolinus provided a control for cystacanth viability.
Beginning 2 weeks postfeeding, daily fecal examinations were made to determine prepatent periods. After demonstrating susceptibility of each of these woodpecker species, three additional red-headed woodpeckers and two additional flickers were similar controls for attempts to infect other avian species. Fifteen cystacanths were fed to each of 15 red-winged blackbirds and 10 starlings. Acanthocephalan eggs were sought by daily fecal examinations beginning 2 weeks postfeeding. After 60 days, blackbirds and starlings were necropsied.

To determine when Mediorhynchus centurorum larvae become infective to woodpeckers, a group of woodroaches were fed eggs and resulting larvae were pipetted into esophaguses of 3 red-headed woodpeckers after 29,39 , and 47 days of development in the woodroaches. Daily examinations were made of the birds' feces beginning 2 weeks postfeeding of larvae and continuing for 45 days or until eggs appeared. If eggs had not appeared after 45 days, birds were necropsied to determine whether nonegg-producing acanthocephalans were present.

Eggs from body cavities of Mediorhynchus centurorum were fed to groups of laboratory-reared American cockroaches, Periplaneta americana, and adult grain beetles, Tenebrio molitor, to study intermediate host specificity in the laboratory. As a control for egg viability, eggs from the same pool used to feed cockroaches and grain beetles were fed to the usual intermediate host, Parcoblatta pensylvanica. All measurements are in micrometers unless otherwise noted.

\section{RESULTS}

During June and July 1971, 1905 arthropods were collected from a swamp and its surrounding pasture, $18 \mathrm{mi}$ south of Baton Rouge, Louisiana, where Mediorhynchus centurorum occurred in more than $60 \%$ of the red-bellied woodpeckers. Table I lists arthropods examined for larval $M$. centurorum. Eight of 228 woodroaches were parasitized by developing M. centurorum (Fig. 1). No other arthropod was found infected.

Eggs from gravid Mediorhynchus centurorum fed in the laboratory to woodroaches hatched

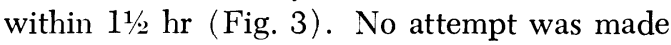
to determine whether hatching occurred sooner or for how long after the $1 \frac{1}{2} \mathrm{hr}$ period it continued. Unhatched eggs remained, however, in woodroach alimentary canals for at least 8 days after ingestion. Forty-three percent of the woodroaches examined 40 or more days after feeding of eggs were infected with from 1 to 11 (mode 1 , median 2, mean 2.4) cystacanths. Student's " $t$ " test did not indicate a significant difference in prevalence or intensity 
TABLE I. Arthropods examined for larval Mediorhynchus centurorum.

\begin{tabular}{|c|c|c|}
\hline Arthropod group & $\begin{array}{c}\text { No. } \\
\text { species }\end{array}$ & $\begin{array}{l}\text { No. } \\
\text { speci- } \\
\text { mens }\end{array}$ \\
\hline Chilopoda & 2 & 5 \\
\hline \multicolumn{3}{|l|}{ Crustacea } \\
\hline Isopoda & 2 & 100 \\
\hline Diplopoda & 1 & 2 \\
\hline \multicolumn{3}{|l|}{ Insecta } \\
\hline \multicolumn{3}{|l|}{ Coleoptera } \\
\hline \multicolumn{3}{|l|}{ Carabidae } \\
\hline Loxandrus lucidulus & 1 & 4 \\
\hline Other & 1 & 2 \\
\hline \multicolumn{3}{|l|}{ Cerambycidae } \\
\hline Prionus sp. & 1 & 17 \\
\hline Other & 1 & 2 \\
\hline Chrysomelidae & 1 & 4 \\
\hline Curculionidae & 4 & 20 \\
\hline \multicolumn{3}{|l|}{ Bostrichidae } \\
\hline Adult & 1 & 22 \\
\hline Larva & 1 & 10 \\
\hline Buprestidae (larva) & 1 & 7 \\
\hline \multicolumn{3}{|l|}{ Elateridae } \\
\hline Adult & 3 & 10 \\
\hline Larva & 3 & 15 \\
\hline Lampyridae & 1 & 1 \\
\hline \multicolumn{3}{|l|}{ Passalidae } \\
\hline Popilus disiunctus & 1 & \\
\hline Adult & & 11 \\
\hline Larva & & 30 \\
\hline \multicolumn{3}{|l|}{ Rhipiceridae } \\
\hline Zenoa picea & 1 & 1 \\
\hline Scarabaeidae & 1 & 3 \\
\hline Staphylinidae & 1 & 2 \\
\hline Tenebrionidae & 5 & 28 \\
\hline Diptera (larva) & 3 & 33 \\
\hline \multicolumn{3}{|l|}{ Dermaptera } \\
\hline Labiidae & 1 & 13 \\
\hline Hemiptera & 2 & 17 \\
\hline \multicolumn{3}{|l|}{ Hymenoptera } \\
\hline Formicidae & 3 & 224 \\
\hline Isoptera & 1 & 39 \\
\hline Lepidoptera (larva) & 3 & 10 \\
\hline \multicolumn{3}{|l|}{ Orthoptera } \\
\hline \multicolumn{3}{|l|}{ Acrididae } \\
\hline Romalea microptera & 1 & 10 \\
\hline \multicolumn{3}{|l|}{ Blattidae } \\
\hline Parcoblatta pensylvanica & 1 & 228 \\
\hline Periplaneta americana & 1 & 20 \\
\hline Gryllidae & 1 & 10 \\
\hline Phasmatidae & 1 & 1 \\
\hline
\end{tabular}

of infection between sexes of woodroaches. Likewise, significant differences could not be demonstrated in prevalence or intensity of infection between woodroaches of varied age groups or between groups of woodroaches fed eggs in suspension from worm body cavities and those fed eggs in moist feces.

Mediorhynchus centurorum eggs had not produced infections in American cockroaches necropsied 50 days after feeding. Infections were produced in control woodroaches and in grain beetles. Larvae recovered from grain beetles 50 days postfeeding of eggs, however, were much less developed than those of the same age from control woodroaches simultaneously fed eggs from the same pool. Fiftyday-old larvae recovered from grain beetles were acanthellae with recognizable proboscis receptacles, but without evidence of genitalia, lemnisci, or proboscis hook development. No cystacanth was recovered from grain beetles; however, no beetle was examined after 50 days postfeeding. Fifty-day-old larvae from woodroaches were fully formed, invaginated cystacanths.

During the course of study, 13 woodpeckers ( 2 red-bellied woodpeckers, 1 hairy woodpecker, 3 flickers, and 7 red-headed woodpeckers), 15 red-winged blackbirds, and 10 starlings were fed Mediorhynchus centurorum cystacanths from laboratory-produced infections. Acanthocephalans produced eggs in all of the woodpeckers except two red-headed woodpeckers fed young larvae to determine at what age cystacanths became infective. The mean prepatent period was 34 days in Centurus carolinus and Melanerpes erythrocephalus, 39 in Dendrocopos villosus, and 35 in Colaptes auratus. The shortest prepatent period was 28 days (one red-headed woodpecker), the longest 39 (one hairy woodpecker), and the overall mean 35. Eggs appeared in feces of one red-bellied woodpecker for 84 days. Duration of egg production was not determined for worms in other birds. No egg was detected in fecal examinations of redwinged blackbirds or starlings and no acanthocephalan was present at necropsy. In each instance eggs in feces demonstrated that infection had occurred in woodpecker controls.

\section{Salient features of development}

Woodroaches with developing acanthocephalans were maintained at room temperatures. For June through September these ranged from $21 \mathrm{C}$ to $32 \mathrm{C}$. During other months the approximate range was $18 \mathrm{C}$ to $24 \mathrm{C}$. Larval development was more rapid during summer months. Salient features of development described here are based on development at summer temperatures with comparisons to similar stages at cooler temperatures. 

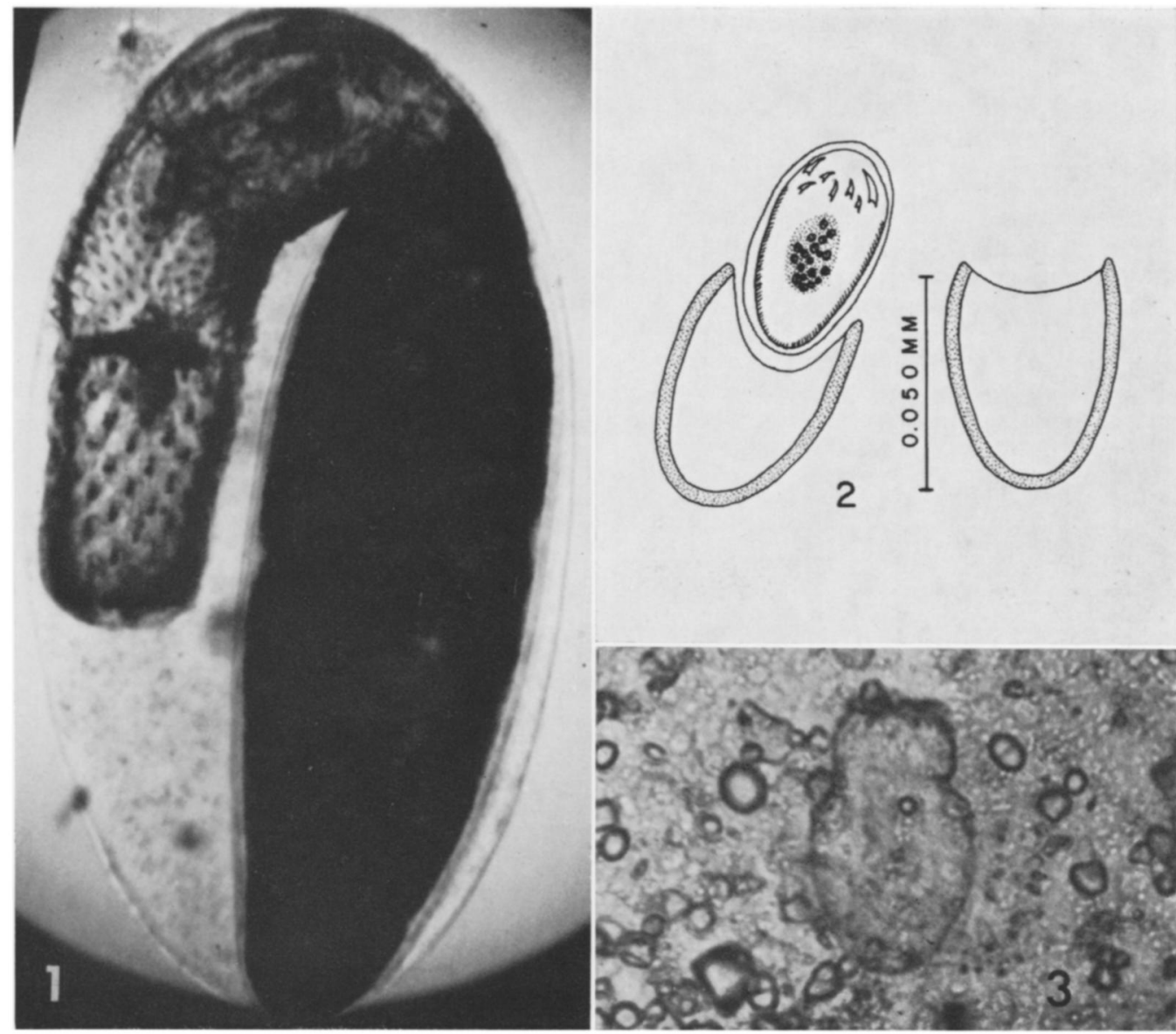

Figures 1-3. Mediorhynchus centurorum. 1. Photograph of acanthella from naturally-infected woodroach. $\times 70$. 2. Camera lucida drawing of empty egg shell and acanthor hatching in wetmount. 3. Photograph of acanthor hatched in woodroach alimentary canal $1 \frac{1}{2} \mathrm{hr}$ postfeeding of eggs. $\times 460$.

Egg and acanthor: Eggs passed naturally in woodpecker feces differed in two regards from those described and illustrated by Nickol (1969) in the original species description. Those in feces were larger (mean 55 by 36 $\mu \mathrm{m})$ and lacked the outer membrane.

Hatched acanthors in woodroach alimentary tracts averaged 70 long by 35 wide and possessed a characteristic constriction (Fig. 3). Some eggs hatched artificially, probably from osmotic pressure, in wet-mount preparations or after storage in tap water. Acanthors artificially hatched by these methods lacked the constriction and remained enclosed in at least one egg envelope (Fig. 2).

Although Mediorhynchus centurorum eggs lack raphes in the fertilization membrane characteristic of some archiacanthocephalans, hatching seemed to occur at a predetermined spot. When hatched in water no acanthor movement was observed, but eggs always split at the end of the acanthor's aclid organ.

Acanthella: Acanthellae were first detected in woodroaches 19 days postfeeding of eggs. Nineteen-day-old acanthellae, along the outside of the alimentary canal, were relatively well developed and enclosed in clear, fluidfilled capsules. Entire capsules averaged 675 long and 165 wide with acanthellae proper measuring 670 by 105 . Proboscis receptacle, cerebral ganglion, and ligament strand were formed. Genital nuclei were present and the 
reproductive system was partially formed. At this time the proboscis was not distinct but hook anlagen, arranged in the adult hook pattern, were discernible. Larvae developing during winter months required 40 days to develop comparably.

After 24 days acanthellae were free of the alimentary canal, enclosed in fluid-filled capsules, elongated, and folded on themselves. Capsules averaged 1130 long and 575 wide with the acanthella proper measuring 2640 by 250. Proboscis hooks were well formed but did not protrude from the hypodermis; well developed lemnisci occupied about one-half of the trunk length, and reproductive structures were identifiable making discernment of the sex possible.

Acanthellae appeared as fully formed juveniles after 29 days, but proboscises had not yet invaginated. Sixty days were required during winter months for larvae to attain this stage of development. These stages were not noticeably different from that illustrated in Figure 1. Acanthocephalans remained enclosed in capsules which now averaged 1590 long and 750 wide. Straightened parasites, dissected from capsules, averaged $2.7 \mathrm{~mm}$ long and 500 at the widest point. About 380 behind the neck, a prominent constriction, 200 across, occurred in the trunk. Average dimensions of proboscis and neck were 540 long by 285 wide and 104 by 293 respectively. Proboscis armature was arranged in 21 to 25 (usually 24) approximately longitudinal rows each with 4 to 6 (usually 5) hooks anteriorly and 4 to 6 (usually 5) spines posteriorly. Thorns of hooks were 34 to 40 long and spines 30 to 36. Largest hook roots were 43 to 49 (mean 46) long. On each side of the neck, an elliptical sensory pit, about 40 by 17 , was located 5 to 9 posteriad to last proboscis spines. Acanthocephalans at this stage of development did not produce infection when 15 were fed to a red-headed woodpecker.

Cystacanth: Cystacanths with proboscises fully invaginated were entangled in malpighian tubules of woodroach hemocoels after 39 days. Infection was not achieved when 15 cystacanths of this age were fed to a red-headed woodpecker. No morphological difference was discovered between these and older cystacanths which proved infective.
After 47 days of development in woodroaches, cystacanths, about 960 long and about 450 wide, proved infective to a red-headed woodpecker. Cystacanths remained infective to woodpeckers for at least 157 additional days. Forty-seven-day-old cystacanths studied by causing proboscis evagination in tap water differed morphologically only slightly from 29 day-old uninvaginated forms. Trunk dimensions of the two age classes were virtually identical. Older forms, however, had slightly longer proboscises (mean 575) and necks (mean 120).

Young forms from birds: Difficulty in capturing sufficient numbers of woodpeckers prevented study of development in definitive hosts by sequential sacrifice. However, the prepatent period ranged from 28 to 39 days and after developing 103 days in woodpeckers, specimens were within the morphological ranges described by Nickol (1969). No attempt was made to study younger specimens (of known ages) from woodpeckers.

\section{DISCUSSION}

Among the Gigantorhynchidae, life cycles are known only for species of the genus Mediorhynchus; M. grandis, M. micracanthus (Rudolphi 1819) Van Cleave 1924, M. papillosus, and now $M$. centurorum. Rizhikov and Dizer (1954) reported natural infections of tenebrionids from the Kara Kum region of U. S. S. R. with M. micracanthus, but did not confirm the life cycle by producing laboratory infections in birds or beetles. Ivashkin and Shmytova (1969) and Kabilov (1969) discovered natural infections of $M$. papillosus in three species of the Tenebrionidae of Crimea and Uzbekistan respectively, but likewise did not produce laboratory infections. Moore (1962) found that eggs of $M$. grandis fed to orthopterans ( 4 species of grasshopper and 1 species of cricket) developed into cystacanths infective to definitive hosts, but found no naturallyinfected orthopteran. Discovery of natural infections of $M$. centurorum in the orthopteran, Parcoblatta pensylvanica, and occurrence of at least partial development in Tenebrio molitor when the tenebrionids were fed eggs in the laboratory is consistent with knowledge of intermediate hosts for other species of the genus. $M$. centurorum is the only species of the family 
for which intermediate host infections have been discovered in nature and the life cycle confirmed in the laboratory.

Although early embryology of Mediorhynchus centurorum was not studied and it is therefore impossible to compare it to that of $M$. grandis as described by Schmidt (1973), later larval development was very similar in the two species. Except for specific differences (primarily proboscis hook size and number), developmental stages of $M$. grandis described by Moore (1962) after 20, 24 to 25 , and 27 to 30 days in grasshoppers are nearly identical to those of $M$. centurorum in woodroaches after 19, 24, and 29 days, respectively.

Artificial hatching of acanthocephalan eggs by alternate drying and wetting has been described by several workers including Manter (1928) and Moore (1942). Uglem (1972) described fundamental differences between eggs artificially hatched in this manner when compared to those hatched in intermediate hosts and found that artificially hatched acanthors of Neoechinorhynchus cristatus were uninfective to ostracod intermediate hosts. Some Mediorhynchus centurorum eggs hatched in water but freed acanthors were inactive and differed in general appearance from those hatched in woodroach alimentary canals (Figs. 2, 3). Schmidt and Olsen (1964), Edmonds (1966), King and Robinson (1967), and Lackie (1972) have successfully hatched eggs in vitro under conditions more closely approximating those encountered in intermediate hosts. Since resulting acanthors, at least of some species (King and Robinson, 1967; Lackie, 1972), are infective when injected into intermediate host hemocoels, these techniques may be more appropriate than drying and wetting for in vitro study of acanthors. The time required after ingestion for $M$. centurorum eggs to hatch was similar to those reported for other acanthocephalan species by DeGiusti (1949), Schmidt and Olsen (1964), and Uglem (1972), but was noticeably less than the 24 to $48 \mathrm{hr}$ (Moore, 1962) for eggs of $M$. grandis.

With the exception of egg size, morphological features of Mediorhynchus centurorum observed throughout this study were in agreement with the original species description even though proboscis armature was slightly more variable than first described. After 29 days in woodroaches the number, size, and arrangement of proboscis hooks and spines agreed with those of adult worms and after 47 days the proboscis was within the adult size range. The neck, however, apparently grows slightly with the trunk after a definitive host is reached. Eggs recovered from woodpecker feces during this study were noticeably larger than those described by Nickol (1969). Since he included measurements of eggs shed by living females in tap water, optical and chemical distortion caused by measuring eggs removed from fixed females or through body walls can only partially account for differences. Whitfield (1970) demonstrated that within the body cavity of Polymorphus minutus fully formed eggs vary considerably in size but that only the larger ones are passed in feces. Perhaps explusion of eggs caused by placing females in tap water results in a large number of smaller, but fully formed, eggs being shed.

Although nearly identical morphologically to infective forms, except that the proboscis had not yet invaginated, 29-day-old Mediorhynchus centurorum were not infective to woodpeckers. After 39 days in woodroaches, proboscises were invaginated, but cystacanths still were uninfective. After 47 days, cystacanths proved infective to woodpeckers. No attempt was made to infect woodpeckers with cystacanths aged between 39 and 47 days. For M. centurorum, there was no great variation in prepatent period, mean 35 days, among definitive host species. The prepatent period is unknown for all other species of the family.

Because Mediorhynchus centurorum and $M$. papillosus are morphologically similar, the possibility was considered that some purported differences might represent only variation induced by an unusual host, Centurus carolinus. Deep penetration producing a large papilla on the woodpecker intestine, resulting trunk constriction, location of lateral sensory pits on the neck, and apparent strict host specificity of $M$. centurorum were of special concern.

Mediorhynchus centurorum differs from $M$. papillosus in possessing lateral sensory pits on the neck that are much closer to the last proboscis spines than are those of $M$. papillosus as well as in details of proboscis armature (Nickol, 1969). The present study demonstrates that sensory pit location and proboscis 
armature of $M$. centurorum cystacanths from woodroaches agree with those of adults from woodpeckers.

Large nodules, approximately $5 \mathrm{~mm}$ by 2 $\mathrm{mm}$, such as those produced on host intestines by Mediorhynchus centurorum are not known to be caused by other species of the genus. Personal observation confirmed that $M$. grandis, M. papillosus, and M. robustus do not produce them in any of a large number of host species, including $M$. grandis from a red-bellied woodpecker. $M$. centurorum produced nodules in each of the avian hosts infected in the laboratory. The earliest any woodpecker was necropsied after being fed cystacanths was 103 days. In that instance each of four $M$. centurorum was removed from an intestinal nodule of a flicker. Nodules were like those of older laboratory and natural infections. On one occasion a red-headed woodpecker died 111 days after being fed cystacanths. Five M. centurorum ( 3 females, 2 males) were embedded in intestinal nodules and the intestine was filled with blood. Each nodule was equal in size to those of older laboratory and natural infections but differed from them in being thin-walled and transparent rather than tough and fibrotic. Intestinal hemorrhage was not observed in any other bird infected with $M$. centurorum.

A long, prominent constricted region of the trunk, corresponding to that portion of the worm inside the nodule, is a distinguishing feature of Mediorhynchus centurorum. Nickol (1969) believed the constriction resulted from compression by host intestinal muscles even though it was unaffected when the acanthocephalan was placed in tap water to force proboscis evagination. After study of development in intermediate hosts, that opinion is unconfirmed. Upon hatching in woodroach alimentary canals, $M$. centurorum acanthors possess a peculiar constriction (Fig. 3) not found, so far as has been determined, in acanthors of other species. This constriction cannot correspond to that of adults, however, since it occurs in the body wall of the acanthor and the body wall of subsequent stages arises from the acanthor's central nuclear mass. M. centurorum juveniles, before invagination, possess constrictions of the trunk (Fig. 1), as do invaginated forms. These constrictions could correspond to those of adults, but similar constrictions have been illu- strated for corresponding stages of $M$. papillosus by Ivashkin and Shmytova (1969) and $M$. grandis by Moore (1962) and these species lack trunk constrictions as adults. It appears as if deep penetration by $M$. centurorum early in the course of infection may prohibit trunk growth typical of other species rather than actually inducing a constriction.

Eight species of Mediorhynchus have been reported from North America, but only four, M. centurorum, M. grandis, M. papillosus, and $M$. robustus, are known to occur regularly. Two, M. bakeri Byrd and Kellogg 1971 and M. colini Webster 1948, both known only from a few specimens from quail, Colinus virginianus, have not been reported since their original descriptions. M. sipocotensis Tubangui 1935 is known only from the Philippines except for a surprising report from Indiana robins by Baker and Hamon (1967). M. emberizae (Rudolphi 1819) Travassos 1923, reported once from Puerto Rico (Whittaker, Schmidt, and Diaz, 1970), is known to occur in at least 16 different host species. M. grandis, M. papillosus, and M. robustus have been reported from 18,43 , and 11 host species, respectively. The degree of host specificity exhibited in nature by $M$. centurorum is therefore surprising. Feeding experiments of this study indicate that $M$. centurorum is capable of maturation in at least three species of Picidae other than Centurus carolinus. These were all included in the original survey and one, Colaptes auratus, was among those examined from the site at which approximately $2 / 3$ of the C. carolinus, but no other species, were infected (Nickol, 1969). Infection and subsequent maturity in hosts other than C. carolinus does not seem to result in loss of infectivity for woodroaches or other woodpeckers. In one series of feeding experiments, eggs collected from a red-bellied woodpecker were used to infect woodroaches and resulting cystacanths produced infection in a red-headed woodpecker. Eggs from this woodpecker were used to produce cystacanths which were in turn fed to a flicker and another redbellied woodpecker. In each case infection occurred and resulting eggs produced cystacanths in woodroaches.

All species of Mediorhynchus of North America, except $M$. centurorum and those known only from a single report, are recorded from 
Agelaius phoeniceus, the usual host of M. papillosus, and Sturnus vulgaris. Failure of $M$. centurorum to infect red-winged blackbirds or starlings suggests inability of this acanthocephalan species to survive in those avian species in nature and augments morphological and behavioral differences between $M$. centurorum and other species of the genus.

\section{ACKNOWLEDGMENTS}

The author is indebted to Dr. Jerome A. Jackson, Mississippi State University, for indispensable aid in capturing red-bellied woodpeckers. Mrs. Shareen Cook Buckner, University of Nebraska, provided much appreciated assistance in caring for very young birds and Dr. J. Harvey Roberts, Louisiana State University, assisted in arthropod identification. Much of the fieldwork was supported by the University of Nebraska Research Council.

\section{LITERATURE CITED}

Baker, J. B., and J. H. Hamon. 1967. Some intestinal parasites of robins from Marion County, Indiana. Proc Indiana Acad Sci 77: $417-419$.

DeGiusti, D. L. 1949. The life cycle of Leptorhynchoides thecatus (Linton), an acanthocephalan of fish. J Parasitol 35: 437-460.

EDMONDS, S. J. 1966. Hatching of eggs of Moniliformis dubius. Exp Parasitol 19: 216226.

Ivashkin, V. M., and G. Ya. Shmytova. 1969. The life cycle of Mediorhynchus papillosus. Tr Gel'mintol Lab 20: 62-63 (In Russian.)

KabiLov, T. 1969. On detection of the acanthella Mediorhynchus papillosus Van Cleave 1916 in beetles. Mater Nauk Konf Vses Obshch Gel'mintol for 1969, Pt 1: 105-107 (In Russian.)
KING, D., AND E. S. RoBinson. 1967. Aspects of the development of Moniliformis dubius. J Parasitol 53: 142-149.

LACKIE, J. M. 1972. The course of infection and growth of Moniliformis dubius (Acanthocephala) in the intermediate host Periplaneta americana. Parasitology 64: 95-106.

Manter, H. W. 1928. Notes on the eggs and larvae of the thorny-headed worm of hogs. Trans Am Microsc Soc 47: 342-347.

Moore, D. V. 1942. An improved technique for the study of the ancanthor stage in certain acanthocephalan life histories. J Parasitol 28: 495.

- 1962. Morphology, life history, and development of the acanthocephalan Mediorhynchus grandis Van Cleave 1916. J Parasitol 48: 76-86.

NickoL, B. B. 1969. Acanthocephala of Louisiana Picidae with description of a new species of Mediorhynchus. J Parasitol 55: 324-328.

Rizhikov, K. M., And Y. B. Drzer. 1954. Biology of Macracanthorhynchus catulinus and Mediorchynchus micracanthus. Dokl Akad Nauk SSSR 95: 1367-1369 (In Russian.)

Sснмid, G. D. 1973. Early embryology of the acanthocephalan Mediorhynchus grandis Van Cleave 1916. Trans Am Micros Soc 92 : 512 516.

—, AND O. W. Olsen. 1964. Life cycle and development of Prosthorhynchus formosus (Van Cleave 1918) Travassos 1926, an acanthocephalan parasite of birds. J Parasitol 50: 721-730.

Uglem, G. L. 1972. The life cycle of Neoechinorhynchus cristatus Lynch 1936 (Acanthocephala) with notes on the hatching of eggs. J Parasitol 50: 721-730.

Whitrield, P. J. 1970. The egg sorting function of the uterine bell of Polymorphus minutus (Acanthocephala). Parasitology 61 : 111-126.

Whittaker, F. H., G. D. Schmidt, and J. G. Diaz. 1970. Helminth parasites of some birds in Puerto Rico. Proc Helminthol Soc Wash 37: 123-124. 